\title{
Publicação impressa da Acta Cirúrgica Brasileira: apoio compartilhado
}

Acreditamos que todos os nossos colegas e leitores tenham percebido o progresso que a Acta vem apresentando. Passamos de edições trimestrais para edições bi-mensais. A qualidade do papel de impressão e as fotografias coloridas têm valorizado a apresentação da informação científica. O criterioso trabalho de nossos revisores tem auxiliado na seleção de trabalhos relevantes. Centros brasileiros e de outros países têm considerado a Acta como veículo de divulgação de artigos originais de pesquisa na área da cirurgia experimental, sendo o único periódico da América Latina especializado nesta área.Entretanto, as dificuldades também tem sido crescentes, particular- mente relacionadas à viabilidade financeira da publicação impressa. O Corpo Editorial da Revista considerou e rejeitou as seguintes alternativas: a redução do número de artigos por volume, o retorno à periodicidade trimestral e a interrupção da edição impressa, mantendo apenas a forma eletrônica (via SciELO). A redução substancial no apoio financeiro pelas agências de fomento, a ausência de interesse por parte da indústria e o custo crescente com a produção e a impressão não têm atingido apenas a Acta Cirúrgica Brasileira. Diversas revistas, incluindo o Brazilian Journal of Medical and Biological Research, passaram parte dos custos aos autores. Optamos por manter o padrão atual da Acta, com a edição impressa e a eletrônica. A partir de $1^{\circ}$ de janeiro de 2004, o custo de cada página impressa será compartilhado com os autores. A cobrança será enviada ao autor principal por ocasião da remessa da prova para a correção final. A Acta manterá a busca continuada por fomento e formas alternativas de apoio que permitam o cancelamento desta cobrança em um futuro próximo. Estamos certos da compreensão da comunidade científica que acredita no avanço continuado da ciência e arte da cirurgia experimental em nosso país.

CORPOEDITORIAL

\section{ACESSOS PELA INTERNET}

\author{
www.scielo.br/acb \\ Instruções aos autores. \\ Consulte antes de enviar o artigo. \\ Esclarecimentos em \\ sgolden@terra.com.br
}

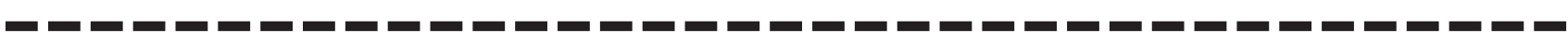

Homepage: www.sobradpec.org.br

Metodologia: www.metodologia.org 